\title{
Design of OSH interventions: a model to improve their actual implementation
}

\begin{abstract}
Background: A multitude of Occupational Safety and Health (OSH) interventions have proven to be effective under controlled conditions, but their implementation in practice is often difficult and interventions may therefore not work as expected, especially when referring to Small and Medium sized Enterprises (SMEs).
\end{abstract}

Methods: In order to solve this challenge, this paper proposes a model for the systematic design of OSH interventions that takes into account the underlying mechanisms and the contextual factors that can enable or disable the behavioural changes needed for an effective implementation of OSH interventions. The performance of the model has been evaluated through fifty interviews.

Results: The interviewees highlighted how the model fosters innovative and more effective solutions, a more effective focus on the aspects that should be considered, a more organic and systematic way of structuring the data, and a holistic and comprehensive view of the factors. The model also highlights specific aspects of contextual factors and mechanisms and it organizes the data in a more systematic and structured fashion.

Conclusion: The evaluation of the model suggests the value of following a structured framework towards implementation of OSH interventions based on the analysis of mechanisms and contextual factors.

Keywords: OSH intervention, Intervention design, Mechanisms, Contextual factors, SMEs.

\section{Introduction}

A multitude of Occupational Safety and Health $(\mathrm{OSH})$ interventions have been proposed by researchers and practitioners (see e.g. Brun and Loiselle (2002) for a taxonomy). Even though the interventions as such have proven to be effective - normally under controlled conditions - implementation for practitioners in practice is often difficult and interventions may therefore not work as expected (Robson, 2001). Therefore, literature points out that the effects of interventions rarely are as strong as expected (Kennedy et al., 2010). A number of researchers have tried to solve this problem by suggesting various models for the design of interventions that should secure a stronger implementation. Most of these models understand interventions as projects and they have adapted phase models from the industrial management literature (Hare and Cameron, 2012). However, even assisted by the phase-models, interventions implemented by practitioners are not necessarily effective, because the implementation is crucially dependent on the mechanisms promoting the social change and on the contextual factors which enable or disable these mechanisms (Pawson, 2002; Pedersen et al., 2012).

In order to consider the mechanisms and the contextual factors enabling the change process during the implementation of OSH interventions, (Pedersen et al, 2012) have proposed a revised realistic evaluation model for the design and evaluation of OSH interventions. It includes factors such as role behaviour, leader and worker motivation, underreporting of injuries, production pressure, unplanned organisational change and accounting. (Van Scheppingen et al, 2015)

More recently, Nielsen and Randall (2013) presented an evaluation framework based on intervention research and process-oriented organization theory. The framework offers suggestions for which elements to include when evaluating organizational interventions. Within the framework, there are four 
overarching categories of elements crucial to intervention evaluation: the organizational "actors", the mental models of those actors, the context of the intervention, and intervention design and process.

Yet, these models can be mainly applied by researchers involved in the design of interventions and they are not fully exploitable by OSH practitioners because they do not guide practitioners into a systematic and structured fashion in the identification of the mechanisms and the contextual factors relevant for the particular OSH interventionn. The models limit themselves to provide a generic definition of mechanisms and contextual factors, assuming that practitioners will be autonomously able to identify specific mechanisms and contextual factors based on their skills and previous experience. The problem is that practitioners could be unable to properly identify specific mechanisms and contextual factors, since the practitioners' decision-making processes can at best be described as governed by bounded rationality, in which heuristics and prior experience play a large role (Hasle, 2011). Moreover, several models assessing context and behavioural mechanisms in accident analysis (Chang and Mosleh, 2007), or human reliability analysis (Kim and Jung, 2003) demonstrate that the analysis of contextual factors and mechanisms is a complex task that needs to be supported by highly structured decision making models.

Practitioners face difficulties, on the one hand, in carrying out a sufficient in-depth analysis of context and mechanism, and, on the other hand, in keeping it sufficiently simple for utilisation in the practical situation. This is particularly relevant for Small- and Medium-sized Enterprises (SMEs), since they have less resources to dedicate to OSH interventions.

This paper aims at providing a solution for this practitioners' challenge by proposing a model for the design of Occupational Safety and Health (OSH) interventions that takes into account the contextual factors and the behavioural mechanisms affecting the implementation of the intervention. The paper is structured as follows. Section 2 presents a review of the literature related to implementation of interventions, with a focus on the realistic analysis and its limitations. Section 3 introduces the proposed framework for the implementation of interventions. Section 4 summarises the methodology used for the evaluation of the model. Section 5 presents and discusses the results of the test. Finally, section 6 takes some conclusions.

\section{OSH Interventions: an overview of the literature}

An OSH intervention can be defined simply as "an attempt to change how things are done in order to improve safety" (Robson, 2001). Brun and Loiselle (Brun and Loiselle, 2002) classify OSH interventions according to three dimensions of work, namely organizational, technical, and human, and two activity levels, namely strategic and operational (Table 1). Examples of interventions include engineering solutions that decrease the probability of a worker engaging in at-risk behaviours, educating and training activities, and safety related policies and procedures.

\begin{tabular}{|c|c|c|c|}
\hline & $\begin{array}{l}\text { Organizational } \\
\text { dimension }\end{array}$ & Technical dimension & Human dimension \\
\hline \multirow[t]{3}{*}{ Strategic } & $\begin{array}{l}\text { Develop organizational } \\
\text { policies }\end{array}$ & $\begin{array}{l}\text { Influence strategic } \\
\text { decisions of an } \\
\text { organization through } \\
\text { technical advice }\end{array}$ & $\begin{array}{l}\text { Make upper management } \\
\text { more aware of OSH } \\
\text { priorities }\end{array}$ \\
\hline & $\begin{array}{l}\text { Draw up an annual } \\
\text { prevention budget }\end{array}$ & $\begin{array}{l}\text { Develop standards for the } \\
\text { use of equipment and raw } \\
\text { materials }\end{array}$ & $\begin{array}{l}\text { Foster OSH militancy } \\
\text { among workers }\end{array}$ \\
\hline & $\begin{array}{l}\text { Write an annual report on } \\
\text { OSH activities }\end{array}$ & & $\begin{array}{l}\text { Involve foremen in } \mathrm{OSH} \\
\text { changes }\end{array}$ \\
\hline
\end{tabular}




\begin{tabular}{|c|c|c|c|}
\hline \multirow[t]{3}{*}{ Operational } & $\begin{array}{l}\text { Investigate } \\
\text { accidents }\end{array}$ & $\begin{array}{l}\text { Conduct studies and } \\
\text { research into technical } \\
\text { safety problems }\end{array}$ & Inform workers \\
\hline & $\begin{array}{l}\text { Manage work accidents } \\
\text { files }\end{array}$ & Carry out risk analysis & $\begin{array}{l}\text { Train workers in safe } \\
\text { work methods }\end{array}$ \\
\hline & $\begin{array}{l}\text { Ensure that OSH policies } \\
\text { and procedures are } \\
\text { correctly applied }\end{array}$ & & $\begin{array}{l}\text { Meet with workers to } \\
\text { discuss OSH }\end{array}$ \\
\hline
\end{tabular}

Table 1: Examples of prevention activities (adapted from Brun and Loiselle, 2002)

OSH interventions are an essential component of the OSH management process, since they allow the elimination of hazards, mitigation of risks, and an upgrade of the OSH conditions and employees' wellbeing. The intervention process includes three key stages: design, implementation, and assessment (Robson, 2001). At a company level, safety practitioners are involved in the design, implementation and assessment of interventions. Other generic practitioners are supposed to benefit from the interventions themselves and in an ideal case are actively involved in the implementation process, adopting the practices suggested by safety practitioners and providing feedback and suggestions (Hasle, 2011; Broberg and Hermund, 2004). On the other hand, safety researchers study OSH interventions, developing ideas and insights for the three steps of the interventions process. The way in which academics and practitioners approach the three steps of the OSH interventions process is different: in general terms, researchers have more resources and less constraints for the design of interventions, and the implementation and assessment happens under controlled conditions and following a structured process (Robson, 2001). Practitioners' interventions, on the other hand, are implemented without highly structured processes and in only partially controlled conditions suggestions (Hasle, 2011). The design is influenced by a potentially biased view or perspective of practitioners, the implementation does not happen under controlled conditions, the assessment can be less formal or not carried at all. There are dedicated streams of literature that deal with researchers and practitioners interventions. Therefore, the following sections will provide an overview of the studies on OSH practitioners role and challenges (Section 2.1) and on OSH interventions research (Section 2.2). Section 2.3 will introduce realistic analysis. This approach has been initially proposed for intervention research and this paper proposes a tool to introduce this simplified approach into the field of practitioners' interventions.

\subsection{OSH Practitioners' role and challenges}

The OSH practitioners are the various people who regularly conduct OSH activities within organizations. They are responsible for planning, implementing, monitoring and reviewing OSH interventions and they can operate in different ways. Brun and Loiselle (2002) argue that there is a wide array of prevention strategies that emerge from the organizational conditions, personal relationships and even the personality traits of the safety practitioners. Similarly, Swuste and Arnoldy (2003) state that the personal effectiveness and the ability to influence and stimulate others of an OSH manager are as important as the quality of an OSH management system. The variety of factors that influences OSH interventions implies that the proper execution of the OSH practitioners' activities can be particularly challenging. Garrigou and Peissel-Cottenaz (2008) underline how OSH practitioners can face challenges and professional distress because of the lack of professional structuring, the marked inequalities in terms of allocated resources, training, and safety policy structuring. Other researchers argue that OSH practitioners act as "political navigators" (Broberg and Hermund, 2004) in pursuing the OSH agenda through the processes of the organisation and they often have to operate in an organizational context that gives a secondary importance to OSH activities (Cutler et al, 1997; Hasle and Jensen, 2006).

\subsection{Researchers' role and challenges - Intervention research}


Several scholars highlighted the importance of analysing the feasibility and effectiveness of OSH interventions (Olsen et al., 2008). (Goldenhar et al, 2001) classify the studies on OSH interventions based on the three key stages of the intervention process: design, implementation, and assessment. Following this classification, the studies on intervention design (called "intervention development research", pp. 617) analyse the OSH needs, the best strategies to deal with these needs, and the barriers to the change process. The studies on intervention implementation (called "Implementation research studies", pp. 618) analyse the implementation process focusing on the material and human components of the interventions and on the differences between planned and actual implementation. The studies on intervention assessment (called "Effectiveness studies", pp. 618) investigate the causes of success or failure of an intervention.

OSH intervention studies face several difficulties, described in book chapters and review papers (Kompier and Kristensen, 2001; Semmer, 2006). Reviewing these studies is beyond the purpose of this paper that aims at contributing to the debate on the implementation of interventions.

Several researchers highlighted the limitation of current studies on the implementation of OSH interventions and the need of better understanding the implementation process.

Griffiths (1999) observes that existing OSH intervention studies focused on causal connection and outcomes of interventions while neglecting the process. Therefore, he suggests that interventions studies should highlight the macro-processes of conceptualization, design and implementation as well as the micro-processes of theoretical mediating mechanism. Similarly, LaMontagne et al. (2007) reviewed the job-stress intervention evaluation literature and they concluded that the published literature focused on effect evaluation while neglecting process evaluation about how interventions were planned and implemented. Pedersen et al. (2012) propose a model reviewing 103 studies, evaluating 4 types of organisational-level workplace intervention and they concluded that many studies referred to implementation but reporting was generally poor and anecdotal in form. Nielsen and Randall (Nielsen and Randall, 2013) summarise the results of a set of review studies and they observe that studies attempting at process evaluation rely on anecdotal data rather than on a structured analysis.

In the light of these calls, several researchers proposed models for the implementation of OSH interventions.

A first group of studies focuses on the factors to be considered for a more successful implementation of the interventions. For instance, Nytrø et al. (2000) highlight the importance of considering the social climate, the opportunities for multi-level participation and negotiation in the design of interventions, the tacit behaviours, and the roles and responsibilities before and during the intervention period. Egan et al. (2009) highlight how existing implementation studies include factors as intervention setting, resources, planning, collaborations, delivery and macro-level socio-economic contexts. Whysall et al. (2006) explored the process of implementing interventions to tackle occupational ill-health and the factors relevant for a successful implementation. The factors cited as key barriers and facilitators include the resistance of workers to changing their behaviour, gaining managerial commitment, and managers' general attitudes towards health and safety. Murta et al. (2007) conduct a systematic review of workplace stress management intervention studies that have incorporated process evaluation and they conclude that the variables most frequently included were recruitment, intervention dose received, participants' attitudes toward intervention, and program reach. Hale et al. (2010) analyse the mechanisms lying behind successful and not successful interventions and they conclude that the more successful interventions rely on constructive dialogue between shop-floor and line management, provide motivation to line managers, and strengthen the monitoring and learning loops in the safety management system. More recent models introduce the idea of different levels or layers of factors that interact in determining the effectiveness of interventions. Pedersen et al. (2012) propose a model based on realistic evaluation which includes factors such as role behaviour, leader and worker motivation, underreporting of accidents/injuries, production pressure, and unplanned organisational change. 
Nielsen and Randall (2013) propose a model of process evaluation that contains three levels of elements: mental model, intervention, and context.

There are other examples of studies that however share the same approaches, proposing one or more factors fostering or hindering the implementation of the interventions (Hale et al., 2010). Thanks to their focus on behavioural characteristics and contextual factors affecting the performance of the workers, these studies help to explain the complex process necessary for the correct implementation of OSH interventions.

However, these studies can provide only a limited support for the design of interventions. Indeed, the implementation is the result of the interaction between a set of mechanisms promoting the social change and a context that enables or disables these mechanisms. Current models did not properly consider the interaction between these two levels: the level of mechanisms and the context that selects, enables, and somehow triggers these mechanisms. For instance, several studies analysed how the desire for rewards can trigger positive behaviours among workers (Hale et al., 2010). However, the desire for these rewards can be more or less effective based on a complex set of factors that can include the organisational culture and the rewarding scheme.

\subsection{Realistic analysis}

Realistic analysis represents a valid theoretical approach for describing the mechanisms promoting or overcoming some key factors in the implementation of intervention and the interplay between those mechanisms and the context in which interventions take place (Pedersen et al., 2012). Realistic analysis was introduced by Pawson et al. (1997), and further developed in Pawson and his colleagues later work (Pawson, 2002; Pawson et al., 2005). It is founded on the ontological position realism, and the key element is to identify what works for whom, under what circumstances, in what respects and how. The generative model of causality, which underpins realistic enquiry, holds that to infer a causal outcome between two events, one needs to understand the underlying mechanisms that connects the events, and the context in which the relationship occurs. The key elements are Context, Mechanism, and Output. Interventions are not presumed to have causal powers in themselves, instead context and mechanisms are seen as the factors which initiate or trigger the causal relationships; for instance, motivation from the key actors is a necessary ingredient for the program to work. The actual outcome of the intervention will vary depending on the intervention, the context, the mechanisms, and the interplay between these, and can be categorized as positive or negative, expected and unexpected. Realistic analysis represents a valid alternative for describing the interplay between personal characteristics and contextual factors within safety interventions because it turns the chain of reasoning of workers into a comprehensive theory of the mechanisms through which the desired change should happen. In the same way, the chain of reasoning and reaction is influenced by some technical and organizational features of the company, and realistic analysis represents these features of the company in terms of contextual factors affecting the mechanisms through which the interventions may enter the operator's mind.

Summing up, it is essential to have a clear understanding of the mechanisms and the role of the context in the implementation of OSH interventions, and realistic analysis represents a valid theoretical approach in order to deal with these issues. Currently, practitioners cannot use the realistic analysis for improving the implementation of OSH interventions. Indeed, in order to use realistic analysis in the industrial practice, practitioners need procedures which are simple, easy to use, systematic, but at the same time, comprehensive, valid and with a strong theoretical foundation. This aspect has not been adequately considered in the reviewed studies, which show two main limitations. Firstly, existing studies do not organize the analysed factors into a comprehensive model that can be used by practitioners in the design of OSH interventions. Each study focuses on a limited number of factors or on specific aspects, and a comprehensive view is missing. In order to properly design OSH interventions, practitioners dealing with the design of OSH interventions should identify all the relevant 
behavioural characteristics and contextual factors affecting the change process. Their knowledge as well as the amount of time and resources they can invest in the design of interventions is however limited. As a consequence, they should be supported by a comprehensive taxonomy of contextual factors and behavioural characteristics that underlie the change process necessary for the implementation of OSH interventions. Some comprehensive taxonomies of contextual factors and behavioural mechanisms have been proposed in the accident analysis (Chang and Mosleh, 2007), and in the human reliability analysis (Kim and Jung, 2003) literature. Nevertheless, these models cannot be simply extended to OSH interventions, because they focus on specific actions in a short term temporal horizon, while the behaviour of the workers relevant for OSH interventions is made up of several different actions, that take place in a longer temporal horizon, and that are influenced by some intervention specific contextual factors. Secondly, practitioners need procedures which are simple, easy to use, and systematic. As a consequence, even if we have a clear theoretical understanding of the factors triggering the behavioural change of the workers, of the factors describing the context in which this behavioural change is embedded, and of the interplay between them, it is necessary to develop a model that drives practitioners in considering these factors during the design of the intervention. However, existing studies are mainly theoretical, and they do not propose any procedure that can be used by practitioners in their industrial practice.

In the light of the above limitations, in this paper we develop a model which supports practitioners in the use of the realistic analysis for an effective plan of the implementation of OSH interventions and which overcomes the abovementioned limitations.

\section{Theoretical framework}

The model includes a taxonomy of mechanisms and contextual factors and a stepwise procedure that allows for a systematic analysis. Before developing the taxonomy, however, it has been necessary to develop a theoretical definition of mechanisms and contextual factors, presented in the following paragraph.

\subsection{Theoretical definition of mechanisms and contextual factors}

In order to produce a definition of mechanisms, we critically reviewed and combined previous definitions. Pederson et al. (2012) defined mechanisms as "relevant personal characteristics of key actors or interpersonal relations between them". We picked the first part of this definition, and we focused on "relevant characteristics of key actors". In our model the mechanisms represent the thought that is instigated or "triggered" by the intervention and through which the workers' behaviour is changed. As a consequence, we narrowed the definition of Pedersen and his colleagues, and we assumed mechanisms as "mental state of key actors". Astbury and Leeuw (2010) discuss the concept of "mechanism" and they attempt to elucidate what mechanisms are and what they are not. They conclude that there are three essential clues located in a "realistic" reading of mechanisms. These are that: 1) mechanisms are usually hidden; 2) mechanisms are sensitive to variations in context; and 3) mechanisms generate outcomes. We picked the last two definitions, since we are already assuming that mechanisms are hidden when we define them as mental states of key actors. In our case, the outcomes generated by mechanisms are the modifications in the performance or in the behaviour of the workers. Finally, Pawson and Tilley (1997) point out how mechanisms are "triggered by a program". We included this aspect in our definition in order to clearly make a distinction between the personal characteristics of actors that are not varying and the ones that vary with the implementation of a particular intervention. For instance, while the motivation of the workers is a personal characteristic that varies on the basis of the particular intervention implemented, the experience of the workers is a cognitive state that cannot be modified by implementing a particular intervention, at least in the short term. 
On the basis of the previous arguments, we define mechanism as "mental state of key actors that are triggered by a program, that vary with changes in the context, and that produce a change in the performance or in the behaviour of the workers". It is important to notice that the change in the mechanisms could enable or disable the desired change. The purpose of practitioners is to promote the mechanisms enabling the social change and to eliminate the mechanisms disabling the desired change.

As for contextual factors, we partially modified the definition of Pedersen et al. (2012) and we define contextual factors as "factors that are not directly related to the performance or to the behaviour of the workers, but that are expected to influence the performance or the behaviour substantially". Indeed, according to the proposed realistic model, the mechanisms are directly related to the performance or to the behaviour of the workers, while the contextual factors create the conditions enabling or disabling mechanisms.

\subsection{Taxonomy of mechanisms and contextual factors}

Having developed a definition of mechanisms and contextual factors, we defined the criteria for the selection of mechanisms and contextual factors adequate for the purposes of the study. These criteria are listed below.

Criterion 1 - Focus on behaviours rather than actions of the workers during the implementation of OSH interventions. The amount of factors which could potentially describe the context and the mechanisms influencing OSH interventions is huge. However, it is possible to select a limited number of relevant factors by focusing on the sole factors that are relevant for the behaviour of the workers during the implementation of OSH interventions rather than for a specific action. A behaviour indicates a complex set of specific actions. An action such as a wrong movement of the operator is relevant in a model for accident analysis, but not so relevant in the more general optic of an OSH intervention. The hypothesis done is that an isolated action has not a relevant influence on the overall effectiveness of the intervention, and it's rather necessary to focus on behaviours happening in a longer temporal perspective.

Criterion 2 - Level of causality adequate for the assessment by SMEs' practitioners. The level of causality (Mohaghegh et al., 2009) describes the position of the factors in the cause-to-effect chain. The choice of the level of causality answers questions such as: should the managerial decisions (hiring, training, etc.) be "bottom layer" factors, or should we move further up in the chain of causality, to top managers' strategic decisions, and do we need to include the regulators' impacts on interventions? In our model, we decided to set the level of causality considering the factors internal to the company that are able to affect the whole behaviour of the workers during the implementation of OSH interventions. This modelling choice is justified by the assumption that it is possible to describe the effect of external factors on the performance of the workers during the implementation of OSH interventions by means of some mediating factors that are internal to the company. For instance, the conditions of the financial markets, which are considered by Pedersen et al. (2012) as a relevant contextual factor, could be described by means of the Perception of available resources, the Trust in management and in the enterprise, and the Rewards. This modelling choice offers several advantages. For instance, the factors could be easily assessed by SMEs' practitioners. It is extremely difficult for OSH practitioners to assess the conditions of the financial markets and their influence on OSH interventions, while it is easy to assess the rewards available for the workers within the company.

Criterion 3 - Level of detail adequate for the development of hypotheses on the overall intervention. The "level of detail" (Mohaghegh et al, 2009) of factors depends on the importance attached to the different dimensions of the factors in terms of their impacts on the model output. For example, there are two possible approaches to make a cause-to-effect interaction between the "human resource system" and "safety climate". The modeller can consider these two factors as global factors. On the other hand, he/she can establish multiple relations between the "human resource system" and different dimensions 
of the "safety climate" (e.g., "perception of the reporting system", "perception of training", etc.). The latter is modelled with a higher level of details. In our model, we decided to set a level of detail optimal for the needs of the realistic analysis, i.e. a level of detail allowing practitioners to develop hypotheses on the whole behaviour of the workers during the implementation of intervention. In order to understand this level, we reviewed some studies specifically developing hypotheses on the mechanisms underlying the behavioural change and the success during OSH interventions. On the basis of these studies, we identified a preliminary set of mechanisms and factors that has been used as a benchmark for the level of detail to be adopted in the taxonomy.

Criterion 4 - Practicality. The factors should be used by ordinary field "safety persons", eventually of a SME, without the need for highly trained experts.

We did not find taxonomies in the literature which covered all the above aspects, neither for the mechanisms nor for the contextual factors. However, we found that some specific factors were able to satisfy all the mentioned criteria and that other factors were potentially suitable after a tailoring process. As a consequence, we performed a conceptualization work and we developed new taxonomies for mechanisms and contextual factors. In some cases, we simply picked factors from existing taxonomies, selecting some factors and excluding others for different reasons. Some factors mentioned in literature are split in different factors. Some were found to be overly broad and as such had to be modelled through other more narrowly defined sets of factors.

We focused on three kinds of studies. First, we reviewed the studies dealing with human error analysis (HEA) or human reliability analysis (HRA) in safety assessment. These studies represent the conditions that influence human performance by means of several 'context factors'. These context factors are referred to by different terms according to method: PSF (performance shaping factors), PIF (performance influencing factors), IF (influencing factors), PAF (performance affecting factors), EPC (error producing conditions), CPC (common performance conditions), and so on. Second, we reviewed the studies dealing with barriers and drivers to OSH interventions; barriers and drivers identify all those factors of context not directly involved in workplace safety intervention, but significantly affecting, respectively hindering and fostering, the outcome of interventions. Third, we reviewed studies dealing with realistic analysis of OSH interventions.

We combined the factors in order to obtain a taxonomy that is as comprehensive as possible. The taxonomy of mechanisms is reported in Table 2, while the taxonomy of contextual factors is reported in Table 3.

\begin{tabular}{|l|l|}
\hline Class & Mechanism \\
\hline \multirow{2}{*}{ Temporary cognitive states } & Memory of previous interventions \\
\cline { 2 - 2 } & Anticipation \\
\hline & Autonomous identification of effective behaviours \\
\hline & Perception of the importance of the intervention \\
\hline & Perception of the consequences associated with the own behaviour \\
\hline & Expectations of the workers \\
\hline & Perception of familiarity with the situation \\
\hline & Proper interpretation of the own role and responsibilities \\
\cline { 2 - 2 } & Perception of available resources \\
\cline { 2 - 2 } & Perception of the complexity of the intervention \\
\hline & Emulation of behaviours of the working group \\
\hline Psychological states & Motivation \\
\hline & Morale \\
\hline & Confidence in own behaviours \\
\hline & Confidence in the chosen intervention \\
\cline { 2 - 2 } & Trust in management and in the enterprise \\
\hline & \\
\hline
\end{tabular}




\begin{tabular}{|l|l|}
\hline & Fear of failure \\
\hline & Stress due to urgent requests \\
\hline & Stress due to the conflict \\
\cline { 2 - 2 } & Frustration \\
\cline { 2 - 2 } & Uncertainty \\
\cline { 2 - 2 } & Attention \\
\hline
\end{tabular}

Table 2. Taxonomy of mechanisms, classified in classes.

\begin{tabular}{|c|c|c|}
\hline Class & Sub-class & Factor \\
\hline \multirow{6}{*}{ Operators } & \multirow{2}{*}{ Physical factors } & Fatigue \\
\hline & & Physical abilities \\
\hline & \multirow{4}{*}{ Cognitive factors } & Skills \\
\hline & & Knowledge \\
\hline & & Experience \\
\hline & & Training \\
\hline \multirow{10}{*}{$\begin{array}{l}\text { Physical work } \\
\text { environment, } \\
\text { equipment and tools }\end{array}$} & \multirow{8}{*}{$\begin{array}{l}\text { Physical work } \\
\text { environment }\end{array}$} & Illumination \\
\hline & & Noise \\
\hline & & Air quality \\
\hline & & Temperature and humidity \\
\hline & & Freedom of movement of workers \\
\hline & & Freedom of communication \\
\hline & & Layout of the plant \\
\hline & & Order and cleanliness \\
\hline & \multirow{2}{*}{ Equipment and tools } & Availability \\
\hline & & Quality \\
\hline \multirow{11}{*}{ Organization factors } & \multirow{7}{*}{ Management and policy } & Plant Policy \\
\hline & & Work and task organization \\
\hline & & Level of supervision \\
\hline & & Production pressure \\
\hline & & Rewards \\
\hline & & Punishments \\
\hline & & Safety culture \\
\hline & \multirow{2}{*}{ Tasks } & Task related difficulties \\
\hline & & Other difficulties \\
\hline & \multirow{2}{*}{ Procedures } & Availability \\
\hline & & Quality \\
\hline \multirow{6}{*}{ Team factors } & \multirow{3}{*}{ Features of the team } & Cohesiveness \\
\hline & & Coordination \\
\hline & & Composition \\
\hline & \multirow{2}{*}{ Communication } & Availability \\
\hline & & Quality \\
\hline & Leadership & Leadership \\
\hline
\end{tabular}

Table 3. Taxonomy of contextual factors, classified in classes and sub-classes.

\subsection{Model}

In order to structure the analysis in a systematic and structured fashion we propose a model for the design of working environment programmes. The idea of the stepwise procedure is to guide managers in a systematic fashion both in the identification of the problem and in the design of the solution. The design of the solution is inspired by the principles of realistic analysis and therefore it includes a list of 
mechanisms and contextual factors. The model therefore adds some supplementary steps to the original procedure proposed by Hasle et al. (2012) and is made up of seven steps:

1. Problem setting. Definition of the OSH challenges of the target group (e.g., "the loads handled by the crane can fall and hit the workers").

2. Intervention design. Selection of the methods and solutions that can improve the working environment and definition of the intervention(s) (e.g. "changing the workers' route so that they do not pass under the crane, and communicating the new procedure via the company bulletin board").

3. Implementation design. Definition of the behavioural change(s) needed for an effective implementation (e.g., "workers must follow the new route indicated").

4. Mechanism selection. Develop theories about mechanism(s) which can motivate the target group to initiate the behavioural change(s). The mechanisms should be selected from the taxonomy proposed in Table 2 (e.g., the enabling mechanism "motivation", i.e. "workers follow the new route because they are very motivated towards safety").

5. Context analysis. Analyse the influence of the context for each of the selected mechanisms; in this step, for each mechanism practitioners should select one or more contextual factors that "condition" the mechanism itself. The contextual factors should be selected from the taxonomy proposed in Table 3 (e.g., "motivation towards safety is influenced by workers' experience and communication between managers and workers").

6. Context assessment. Assess the adequacy of the contextual factor in the current context of the firm (e.g., "workers' experience is poor, and is not such as to activate workers' motivation for safety" and "communication between managers and workers is effective with respect to workers' motivation for safety".

7. Context design. Develop design recommendations for the intervention which build on the results of the four preceding steps (e.g., "the experience of workers cannot be changed in the short term, and we cannot replace workers" and "communication between managers and workers can be improved by communicating the new path not only through the bulletin board, but also through posters").

\section{Methodology used for the evaluation of the model}

Fifty safety officers (i.e. safety managers or manager knowledgeable of OSH issues and responsible of OSH investments) were interviewed, with the support of a questionnaire. The questionnaire was divided into three sections. In the first part, some enterprise characteristics were asked. The data and information asked were mainly related to the sector the firm operates in, the firm size both in terms of turnover and number of employees, the products/services delivered, the industrial processes and organisations adopted, and OSH organisation, followed by information about the respondent (i.e. role, expertise, education, etc.). In the second part, the safety officers were asked to use the model. Following the model's steps, they identify some (usually, no more than three) OSH challenges, and, for each of them, they described some interventions they claimed, from their expertise, to tackle such issues. Then, for each of the interventions, they identified the behavioural change(s) needed for an effective implementation. For each behavioural change, they described the mechanism(s) that can enable (or disable) the behavioural change, selecting one(s) from the taxonomy proposed. In turn, for each mechanism, practitioners had to select one or more contextual factors that could "condition" the mechanism itself, also assessing it (or them) in the current context of the firm. At the end, they were asked to provide recommendations for the intervention implementation, stemming from the adoption of the previous steps of the methodology. In the third part, practitioners have been asked to evaluate the performance of the framework taking into account three main criteria: usefulness, completeness, and difficulty of use, responding to the questions reported in Table 4. 
Table 4. Questions used for the assessment of the performance of the model in the third part of the questionnaire.

\begin{tabular}{|c|c|}
\hline Criterion & Questions \\
\hline Usefulness & $\begin{array}{l}\text { 1. DESIGN: Was the model useful for the design of the intervention? Why? } \\
\text { Did the model help to identify some factors that you did not identify? Did } \\
\text { the model help you to better structure what you had in your mind? } \\
\text { 2. INTERACTION: While setting the improvements of the intervention, was } \\
\text { it helpful to consider the interaction between mechanisms and contextual } \\
\text { factors? Why? Were you able to identify - thanks to this interaction - } \\
\text { some aspects of the contextual factors that you would have neglected } \\
\text { without the model? } \\
\text { 3. IMPROVEMENT: Do the improvements introduced thanks to the model } \\
\text { compensate the difficulty of use? } \\
\text { 4. RESULT: Would you obtain the same results without the support of the } \\
\text { model? }\end{array}$ \\
\hline Completeness & $\begin{array}{l}\text { 5. MECHANISM: Do you think that the list of mechanisms is complete? } \\
\text { 6. CONTEXTUAL FACTOR: Do you think that the list of contextual factors } \\
\text { is complete? }\end{array}$ \\
\hline Difficulty of use & $\begin{array}{l}\text { 7. STEP: Which was the most difficult step performed during the use of the } \\
\text { model? Why? }\end{array}$ \\
\hline
\end{tabular}

The size and sector of the firms and the role of the responding safety officers are reported in detail in Table 5, and summarised in Figure 1. The Small and Medium sized Enterprises (SMEs) - as defined in the 2003/361/EC Recommendation (European Commission, 2003) - mainly belong to the most important manufacturing sectors of the Lombardy Region in Italy in terms of employees and turnover and they have been classified according to the International Standard Industrial Classification of All Economic Activities "ISIC rev.4". As it can be argued from Table 5, the SMEs have been divided into three classes: Small (SEs, $10<$ employees $\leqslant 49$ ), Medium (MEs, $50<$ employees $\leqslant 99$ ), and MediumLarge Enterprises (MLEs; $100<$ employees $\leqslant 250$ ) Cagno et al., (2014).

Table 5. The size ( $\mathrm{SE}=$ small; $\mathrm{ME}=$ medium; $\mathrm{MLE}=$ medium-large) and sector of the firms, and role of the responding safety officer.

\begin{tabular}{cccccc}
\hline Enterprise & Size & & Sector & Role \\
\hline 1 & ME & C25 & - & Manufacture of fabricated metal products & Safety Manager \\
\hline 2 & MLE & C25 & - & Manufacture of fabricated metal products & Safety Manager \\
\hline 3 & ME & C25 & - & Manufacture of fabricated metal products & Safety Manager \\
\hline 4 & ME & C28 & - & Manufacture of machinery and equipment n.e.c. & Safety Manager \\
\hline 5 & ME & C10 & - & Manufacture of food products & Safety Manager \\
\hline 6 & MLE & G46 & - & Wholesale trade, except of motor vehicles and motorcycles & Safety Manager \\
\hline 7 & MLE & C22 & - & Manufacture of rubber and plastics products & Safety Manager \\
\hline 8 & MLE & C28 & - & Manufacture of machinery and equipment n.e.c. & Safety Manager \\
\hline 9 & SE & C22 & - & Manufacture of rubber and plastics products & Other \\
\hline 10 & ME & C27 & - & Manufacture of electrical equipment & Safety Manager \\
\hline 11 & ME & C33 & - & Repair and installation of machinery and equipment & Safety Manager \\
\hline 12 & ME & C28 & - & Manufacture of machinery and equipment n.e.c. & Safety Manager \\
\hline 13 & ME & C33 & - & Repair and installation of machinery and equipment & Other \\
\hline 14 & ME & C25 & - & Manufacture of fabricated metal products & Other \\
\hline 15 & ME & C25 & - & Manufacture of fabricated metal products & Other \\
\hline 16 & SE & C25 & - & Manufacture of fabricated metal products & Other \\
\hline
\end{tabular}




\begin{tabular}{|c|c|c|c|c|c|}
\hline 17 & $\mathrm{ME}$ & $\mathrm{C} 25$ & - & Manufacture of fabricated metal products & Other \\
\hline 18 & SE & $\mathrm{C} 17$ & - & Manufacture of paper and paper products & Safety Manager \\
\hline 19 & $\mathrm{ME}$ & $\mathrm{C} 22$ & - & Manufacture of rubber and plastics products & Safety Manager \\
\hline 20 & $\mathrm{ME}$ & $\mathrm{C} 28$ & - & Manufacture of machinery and equipment n.e.c. & Safety Manager \\
\hline 21 & ME & $\mathrm{C} 28$ & - & Manufacture of machinery and equipment n.e.c. & Safety Manager \\
\hline 22 & $\mathrm{ME}$ & $\mathrm{C} 26$ & - & Manufacture of computer, electronic and optical products & Other \\
\hline 23 & SE & F 43 & - & Specialized construction activities & Other \\
\hline 24 & $\mathrm{ME}$ & C32 & - & Other manufacturing & Safety Manager \\
\hline 25 & SE & $\mathrm{C} 28$ & - & Manufacture of machinery and equipment n.e.c. & Safety Manager \\
\hline 26 & $\mathrm{ME}$ & G46 & - & Wholesale trade, except of motor vehicles and motorcycles & Safety Manager \\
\hline 27 & $\mathrm{ME}$ & E36 & - & Water collection, treatment and supply & Safety Manager \\
\hline 28 & MLE & M74 & - & Other professional, scientific and technical activities & Safety Manager \\
\hline 29 & MLE & $\mathrm{C} 32$ & - & Other manufacturing & Safety Manager \\
\hline 30 & MLE & D35 & - & Electricity, gas, steam and air conditioning supply & Safety Manager \\
\hline 31 & $\mathrm{ME}$ & $\mathrm{C} 26$ & - & Manufacture of computer, electronic and optical products & Safety Manager \\
\hline 32 & MLE & $\mathrm{C} 22$ & - & Manufacture of rubber and plastics products & Safety Manager \\
\hline 33 & $\mathrm{ME}$ & $\mathrm{C} 28$ & - & Manufacture of machinery and equipment n.e.c. & Safety Manager \\
\hline 34 & MLE & $\mathrm{C} 20$ & - & Manufacture of chemicals and chemical products & Safety Manager \\
\hline 35 & $\mathrm{ME}$ & F41 & - & Construction of buildings & Safety Manager \\
\hline 36 & MLE & D35 & - & Electricity, gas, steam and air conditioning supply & Safety Manager \\
\hline 37 & MLE & D35 & - & Electricity, gas, steam and air conditioning supply & Safety Manager \\
\hline 38 & MLE & M71 & - & Architectural and engineering activities & Safety Manager \\
\hline 39 & $\mathrm{ME}$ & $\mathrm{C} 28$ & - & Manufacture of machinery and equipment n.e.c. & Safety Manager \\
\hline 40 & MLE & $\mathrm{C} 32$ & - & Other manufacturing & Safety Manager \\
\hline 41 & $\mathrm{ME}$ & $\mathrm{C} 20$ & - & Manufacture of chemicals and chemical products & Safety Manager \\
\hline 42 & MLE & F41 & - & Construction of buildings & Safety Manager \\
\hline 43 & $\mathrm{ME}$ & $\mathrm{C} 20$ & - & Manufacture of chemicals and chemical products & Safety Manager \\
\hline 44 & $\mathrm{ME}$ & $\mathrm{C} 20$ & - & Manufacture of chemicals and chemical products & Safety Manager \\
\hline 45 & MLE & $\mathrm{C} 20$ & - & Manufacture of chemicals and chemical products & Safety Manager \\
\hline 46 & $\mathrm{ME}$ & $\mathrm{C} 20$ & - & Manufacture of chemicals and chemical products & Other \\
\hline 47 & $\mathrm{ME}$ & E38 & - & Waste collection, treatment and disposal activities & Safety Manager \\
\hline 48 & $\mathrm{ME}$ & D35 & - & Electricity, gas, steam and air conditioning supply & Safety Manager \\
\hline 49 & $\mathrm{ME}$ & $\mathrm{C} 20$ & - & Manufacture of chemicals and chemical products & Safety Manager \\
\hline 50 & MLE & $\mathrm{C} 22$ & - & Manufacture of rubber and plastics products & Safety Manager \\
\hline
\end{tabular}

Figure 1. Distribution of the size ( $\mathrm{SE}=$ small; $\mathrm{ME}=$ =medium; MLE=medium-large) and sector of the firms, and role of the responding safety officer.

Size

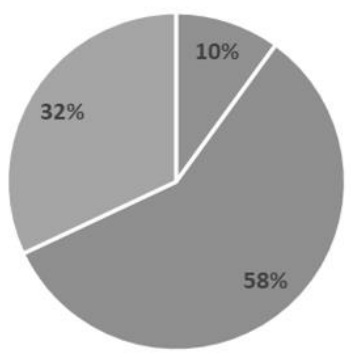

Sector

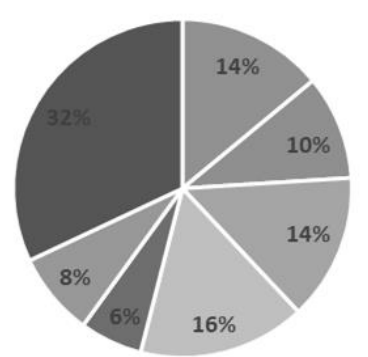

Role

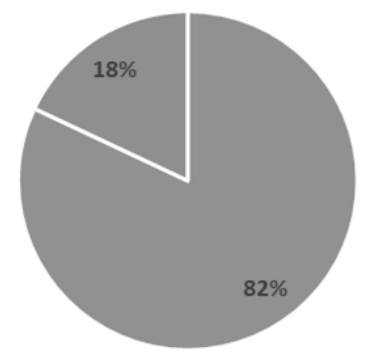




\section{Results and discussion}

The results of the evaluation include the mechanisms and contextual factors identified through the framework (section 3.1) and the practitioners' assessment of the performance of the model (section 3.2).

\subsection{Mechanisms and contextual factors}

All the 50 practitioners, after a brief description of the steps (i.e. the one reported in section 3 ), were able to respond to all the questions of the second part of the questionnaire, in which they had to use the model and the taxonomies, providing evidence of the user-friendliness of the methodology.

The first result of the evaluation consists of the mechanisms and contextual factors that the companies identified for the specific interventions, even though the limited size of the sample allows only for some initial considerations.

The detailed results are shown in Appendix. In the Appendix table, the 274 interventions (by kind) described by the safety officers are grouped by the 22 mechanisms (on the rows) and, then, divided (on the columns) by the 4 classes of contextual factors. Moreover, it is reported (information reported in the single cell) the firm size and the assessment of the adequacy of the contextual factor in the current context of the firm (together with the identifying number of the firm).

Both mechanisms enabling and disabling the behavioural change were found to be equally used, also regardless of firm size. Two mechanisms (i.e. "Expectations of the workers" and "Uncertainty") were not detected at all.

The most frequent (in absolute terms, with respect to the number of interventions) mechanisms enabling the behavioural change are the "Perception of the consequences associated with the own behaviour" $(32 \%)$, the "Autonomous identification of effective behaviours" (23\%), and "Motivation" (19\%) (Figure 2).

Figure 2. Most frequent (in absolute terms, with respect to the number of interventions) mechanisms enabling the behavioural change (up to $99 \%$ of occurrences).

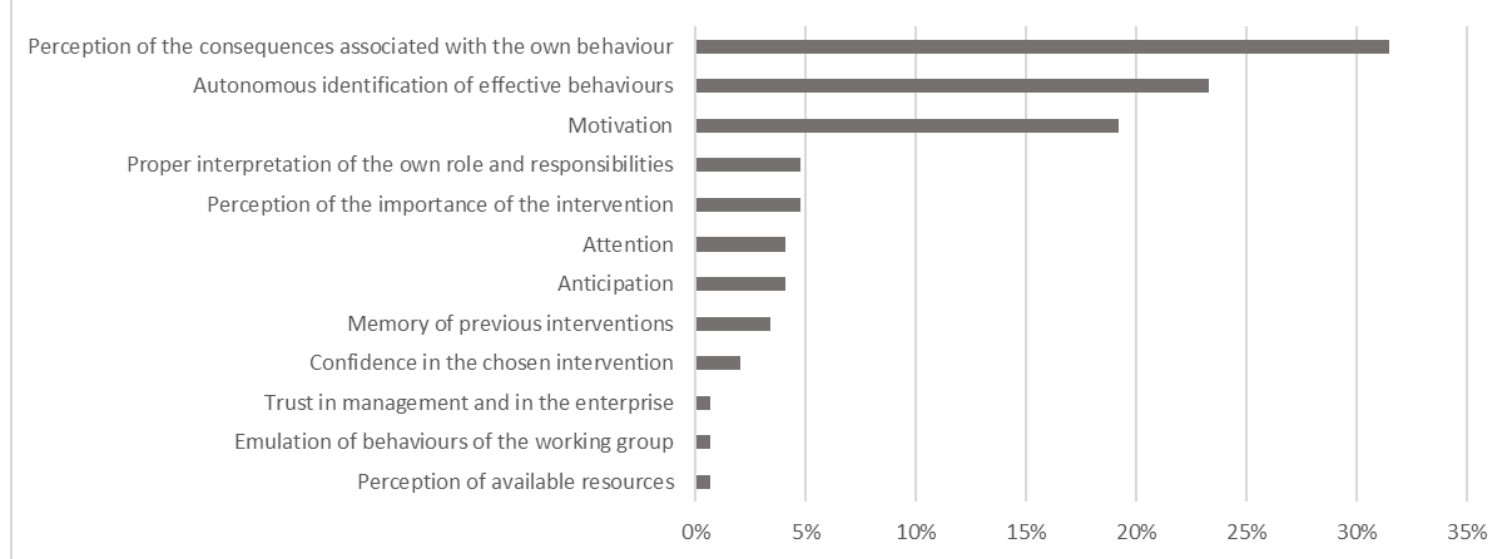


If we consider the most frequent mechanism enabling the behavioural change we found in a company (i.e., found at least once) are the "Perception of the consequences associated with the own behaviour" (88\%), the "Autonomous identification of effective behaviours" (60\%), and "Motivation" (50\%).

While the importance of the perceived consequences is well known in the scientific literature (see e.g. Zohar, [2014]), it is interesting to observe the importance of a mechanism like the autonomous identification of effective behaviours, in the context of SMEs that is traditionally described as dominated by the owner-manager with respect to the safety management (Legg et al., 2015; Kvorning et al., 2015).

For larger enterprises, the "Perception of the consequences associated with the own behaviour" is more frequent, while motivation is less frequent. This result challenges again the view of small enterprises dominated by an owner manager and suggests that the less formalized management systems of a small enterprise could create a space for the employee to act in a proactive way with respect to OHS.

The most frequent contextual factor identified for the "Perception of the consequences associated with the own behaviour" are related to the Operators themselves. The most frequent contextual factor identified for the "Autonomous identification of effective behaviours" and "Motivation" are related to organization factors. This result can suggest that while trying to relate mechanisms and contextual factors, the users of the model tend to combine operator related factors with more tangible and objective contextual factors and, on the other hand, they combine more context dependent mechanisms (such as the perception of the consequences associated with the own behaviour, since the consequences are stated by company policies) with contextual factors more related to operator. In few words, the users tend to create dyads of Operator/context based mechanisms with context/operator based contextual factors.

The most frequent mechanisms disabling the behavioural change are "Perception of familiarity with the situation" (24\%), "Confidence in own behaviours" (22\%), "Stress due to urgent requests" (14\%), and "Emulation of behaviours of the working group" (9\%) (Figure 3).

Figure 2. Most frequent (in absolute terms, with respect to the number of interventions) mechanisms disabling the behavioural change (up to $99 \%$ of occurrences).

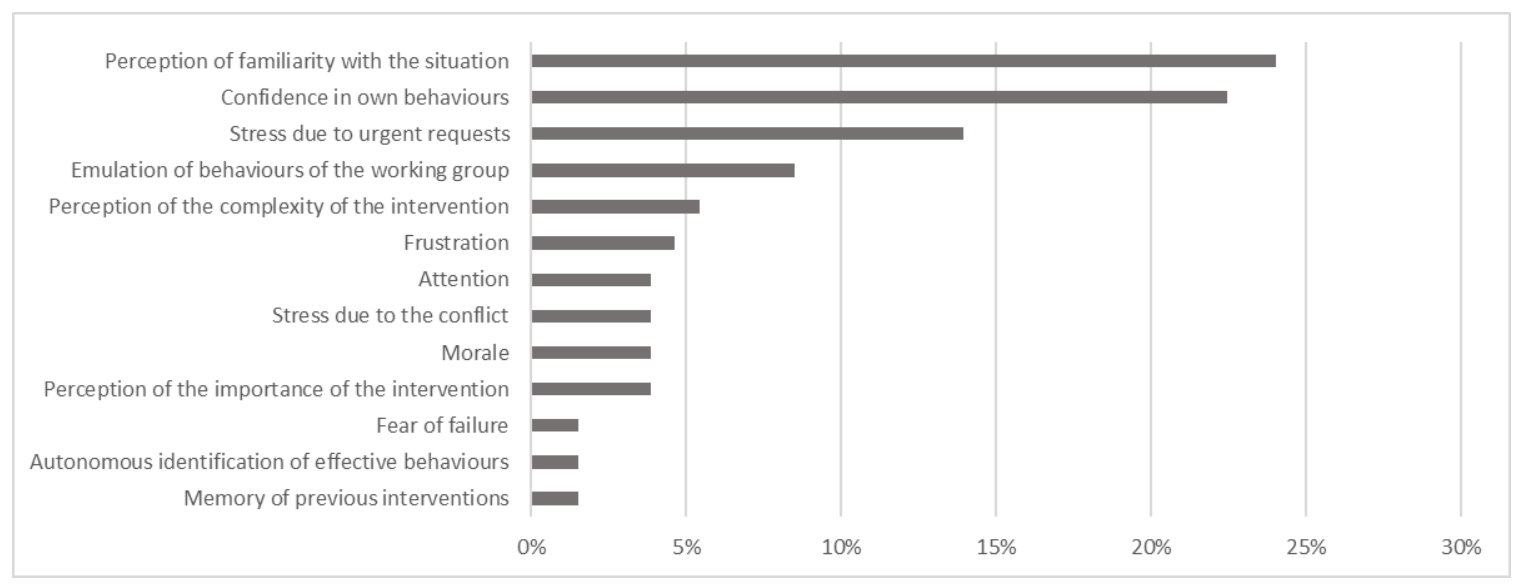

If we consider the most frequent mechanism disabling the behavioural change we found in a company (i.e., found at least once) are the "Perception of familiarity with the situation" (60\%), the "Confidence in own behaviours" (56\%), "Stress due to urgent requests" (36\%), and "Emulation of behaviours of the working group" $(22 \%)$. 
This result is in line with the previous one indicating that a key enabling mechanisms is the autonomous identification of effective behaviours. Indeed, the two results suggests that it is possible to find in smaller enterprises a worker that proactively behaves in terms of OHS, but that can overestimate his capability of controlling and managing the change.

With respect to the firm size, the frequency of mechanism enabling the behavioural change for larger companies seems to decrease for the "Perception of familiarity with the situation" and, in particular, for "Confidence in own behaviours". Like in the previous case, the highlighted consequences of proactive workers are particularly evident for SMEs.

The most frequent contextual factor identified for the "Perception of familiarity with the situation" are related to the Operators themselves. The most frequent contextual factor identified for the "Confidence in own behaviours" and "Stress due to urgent requests" are related to organization factors. The most frequent contextual factor identified for the "Emulation of behaviours of the working group" are related to team factors.

The practitioners identified several interesting combinations of mechanisms and contextual factors, which introduce novel insights also for the safety literature. For instance, the "Perception of familiarity with the situation" influenced by the "layout of the plant" has been identified as a mechanism disabling the desired performance. According to the authors' knowledge, the layout of the plant has never been related to the Perception of familiarity with the situation in previous safety literature.

\subsection{Performance of the model}

Almost all the practitioners evaluated the performance of the model taking into account the usefulness, the completeness, and the difficulty of use. These results are shown in Table 6. In that table, the result of the assessment of the performance of the model is reported by means of a five-point scale $(++=$ definitely yes (unreserved); $+=$ yes; $o=$ neutral (neither yes nor no); - = no; -- = definitely no; n.a. = she/he does not know / does not answer) for questions from 1 to 6 (i.e. usefulness and completeness; ref. to Table 4), and identifying (with a "X") the step(s) of the model in which the they found the main difficulty for question 7 (i.e. difficulty of use; ref. to Table 4).

Table 6. Assessment of the model performance made by practitioners that used it.

\begin{tabular}{|c|c|c|c|c|c|c|c|c|c|c|c|c|c|}
\hline \multirow{3}{*}{ Enterprises } & \multicolumn{13}{|c|}{ Questions (ref. to Table 4) } \\
\hline & \multirow{2}{*}{ 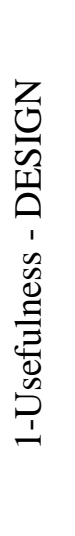 } & \multirow{2}{*}{ 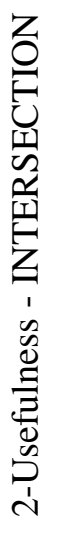 } & \multirow{2}{*}{ 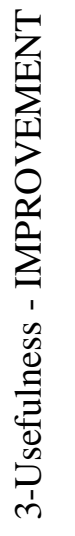 } & \multirow{2}{*}{ 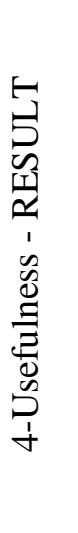 } & \multirow{2}{*}{ 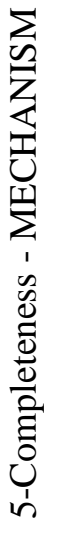 } & \multirow{2}{*}{ 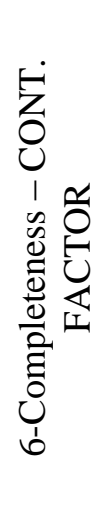 } & \multicolumn{7}{|c|}{ 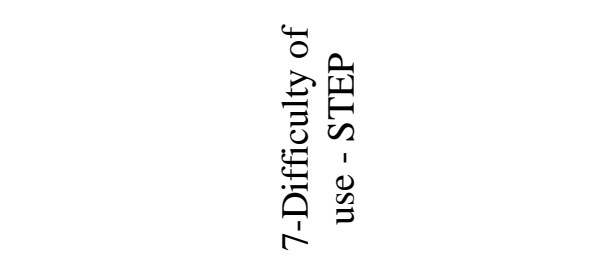 } \\
\hline & & & & & & & 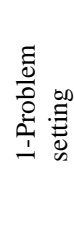 & 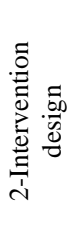 & 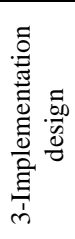 & 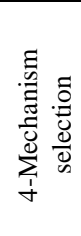 & 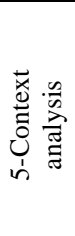 & 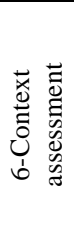 & 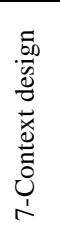 \\
\hline 1 & ++ & ++ & ++ & n.a. & n.a. & n.a. & & & & & & & $X$ \\
\hline 2 & ++ & ++ & - & ++ & n.a. & n.a. & & & & & $\mathrm{X}$ & & $X$ \\
\hline 3 & ++ & ++ & ++ & -- & n.a. & n.a. & & & & $X$ & $\mathrm{X}$ & & \\
\hline 4 & ++ & ++ & + & n.a. & n.a. & n.a. & & & & $\mathrm{X}$ & & & \\
\hline 5 & ++ & ++ & ++ & -- & n.a. & n.a. & & $X$ & & & & $X$ & \\
\hline
\end{tabular}




\begin{tabular}{|c|c|c|c|c|c|c|c|c|c|c|c|c|c|}
\hline 6 & n.a. & n.a. & n.a. & n.a. & n.a. & n.a. & n.a. & n.a. & n.a. & n.a. & n.a. & n.a. & n.a. \\
\hline 7 & ++ & ++ & ++ & - & n.a. & n.a. & & & & $X$ & & & \\
\hline 8 & ++ & ++ & ++ & - & n.a. & n.a. & & & & & & & $X$ \\
\hline 9 & + & ++ & + & - & n.a. & n.a. & & & & & $X$ & $\mathrm{X}$ & \\
\hline 10 & ++ & ++ & + & + & n.a. & n.a. & & & & & $\mathrm{X}$ & & \\
\hline 11 & ++ & ++ & ++ & n.a. & ++ & ++ & & & & & & & $X$ \\
\hline 12 & ++ & ++ & ++ & n.a. & ++ & ++ & & & & & & & $X$ \\
\hline 13 & ++ & ++ & ++ & n.a. & ++ & ++ & & & & & & & $X$ \\
\hline 14 & + & ++ & ++ & n.a. & ++ & ++ & & & $\mathrm{X}$ & & & & \\
\hline 15 & ++ & ++ & ++ & n.a. & ++ & ++ & & & & & $X$ & & \\
\hline 16 & ++ & ++ & ++ & n.a. & ++ & ++ & & & & & $\mathrm{X}$ & $\mathrm{X}$ & \\
\hline 17 & ++ & ++ & ++ & n.a. & ++ & ++ & & & & & $\mathrm{X}$ & $\mathrm{X}$ & \\
\hline 18 & ++ & ++ & + & n.a. & ++ & ++ & & & & & $\mathrm{X}$ & $X$ & \\
\hline 19 & ++ & ++ & ++ & n.a. & ++ & ++ & & & & & & & $X$ \\
\hline 20 & ++ & ++ & ++ & n.a. & ++ & ++ & & & & & & & $X$ \\
\hline 21 & ++ & ++ & ++ & -- & ++ & ++ & & & & & & & $X$ \\
\hline 22 & ++ & ++ & ++ & -- & ++ & ++ & & $X$ & $X$ & & & & \\
\hline 23 & ++ & ++ & ++ & -- & ++ & ++ & & & & & & & $\mathrm{X}$ \\
\hline 24 & ++ & ++ & ++ & -- & ++ & ++ & & & & $X$ & & & \\
\hline 25 & ++ & ++ & ++ & -- & + & ++ & & & & & & & $\mathrm{X}$ \\
\hline 26 & ++ & ++ & ++ & - & ++ & ++ & & & & X & & & $X$ \\
\hline 27 & ++ & ++ & ++ & -- & + & ++ & & & & & & & $X$ \\
\hline 28 & ++ & ++ & ++ & + & ++ & + & & & & & $X$ & & \\
\hline 29 & -- & -- & -- & ++ & ++ & ++ & n.a. & n.a. & n.a. & n.a. & n.a. & n.a. & n.a. \\
\hline 30 & ++ & ++ & ++ & --- & ++ & ++ & & & & & & & $\mathrm{X}$ \\
\hline 31 & 0 & + & ++ & ++ & ++ & ++ & & & & & & & $X$ \\
\hline 32 & o & ++ & ++ & ++ & ++ & ++ & & & & & & & \\
\hline 33 & ++ & ++ & ++ & + & ++ & ++ & & & & & & & $\mathrm{X}$ \\
\hline 34 & + & + & -- & ++ & ++ & ++ & n.a. & n.a. & n.a. & n.a. & n.a. & n.a. & n.a. \\
\hline 35 & + & ++ & ++ & + & ++ & ++ & & & & & & & $\mathrm{X}$ \\
\hline 36 & + & + & ++ & ++ & ++ & ++ & & & & & & & $X$ \\
\hline 37 & ++ & ++ & ++ & ++ & ++ & ++ & & & & & & & $X$ \\
\hline 38 & ++ & ++ & ++ & ++ & ++ & ++ & & & & & & & $X$ \\
\hline 39 & + & ++ & ++ & ++ & ++ & ++ & & & & & & & $\mathrm{X}$ \\
\hline 40 & + & n.a. & --- & ++ & ++ & ++ & & & & & & & $X$ \\
\hline 41 & 0 & $\mathrm{o}$ & + & 0 & ++ & ++ & & & & & & & $X$ \\
\hline 42 & + & + & ++ & $\mathrm{O}$ & ++ & ++ & & & & & & & $X$ \\
\hline 43 & + & + & -- & ++ & ++ & ++ & & & & & & & $X$ \\
\hline 44 & + & ++ & ++ & ++ & ++ & ++ & & & & & & & $X$ \\
\hline 45 & + & + & ++ & ++ & ++ & ++ & & & & & & & $X$ \\
\hline 46 & $\mathrm{O}$ & + & ++ & ++ & ++ & ++ & & & & & & & $X$ \\
\hline 47 & + & ++ & ++ & ++ & ++ & ++ & & & & & & & $X$ \\
\hline 48 & + & + & ++ & ++ & ++ & ++ & & & & & & & $X$ \\
\hline 49 & + & ++ & ++ & ++ & ++ & ++ & & & & & & & $X$ \\
\hline 50 & + & ++ & ++ & + & ++ & ++ & & & & & & & $X$ \\
\hline \multicolumn{14}{|l|}{ TOTAL } \\
\hline$++($ or $X)$ & 29 & 38 & 39 & 17 & 38 & 39 & 0 & 2 & 2 & 5 & 9 & 5 & 32 \\
\hline+ & 15 & 8 & 5 & 5 & 2 & 1 & & & & & & & \\
\hline 0 & 4 & 1 & 0 & 2 & 0 & 0 & & & & & & & \\
\hline- & 0 & 0 & 1 & 4 & 0 & 0 & & & & & & & \\
\hline-- & 1 & 1 & 4 & 9 & 0 & 0 & & & & & & & \\
\hline n.a. & 1 & 2 & 1 & 13 & 10 & 10 & 3 & 3 & 3 & 3 & 3 & 3 & 3 \\
\hline
\end{tabular}




\section{Question 1- Usefulness - DESIGN}

44 of the interviewees confirmed that the model was useful (and 29 judged it very useful) for the design of the intervention. The reasons reported by the interviewees include the possibility of defining innovative and more effective solutions (for enterprises 16, 17, 18, 19, and 20), a better focus on the aspects that should be considered (for enterprises 3,12, 15, 22, 25, 33, and 38), a more organic and systematic way of structuring the data (for enterprises $1,5,14,35,36$, and 37), and a holistic and comprehensive view on the factors (for enterprises 7, 11, 21, 30, 39, and 40). 5 of the interviewees argued that the model is not useful. One of these (enterprise 31) argued how the model is too theoretical, and how collaborating with workers is more effective for understanding their behaviour. Another one (enterprise 32) underlined how to model is similar to other tools used in the enterprise. A third one (enterprise 46) argued that the model is not useful in practice because in the workplace this result can be explained considering the human behaviour is too inconstant and it cannot be described by such a structured model. Overall, the results suggest the usefulness of a more structured approach for the design of OHS interventions in SMEs, and the possibility of extending to practitioner's models for OHS interventions traditionally addressed to OHS researchers.

Analysing the stratified data, it is possible to make some observations on the influence of role and size. Regarding the role, the safety managers seem to have a perception of the usefulness of the model slightly lower than the "other" OHS practitioners. This result can be explained considering that safety managers with a considerable experience could overestimate their capability of controlling risk and assume to already have the necessary and sufficient tools for a full and comprehensive risk assessment (Hasle et al., 2012). The "others" are probably more open to the novelty and, having less specific skills and experience, show a slightly greater interest in an innovative approach.

Regarding the size, the perceived usefulness clearly decreases from smaller to larger organizations. The result could be explained considering that in general, small SMEs are characterised by management by the owner in a personalized non-formal manner (Legg et al., 2015) and therefore the introduction of a structured approach has a considerable impact in terms of performance. By contrast, large companies, with greater resources, may consider to already have all the tools needed to assess the risks in their workplaces. The medium-sized companies are positioned midway between these two positions.

\section{Question 2 - Usefulness - INTERSECTION}

Most (46 out of 50) of the respondents answered positively and in many cases (i.e. 38) very positively to the question regarding the usefulness of considering the interaction between mechanisms and contextual factors. The reasons listed included the identification of more aspects and more factors that would not emerge otherwise (enterprises 1, 4, 5, 11, 21, 23, 24, 26, and 27), a level of detail in the analysis that could not be achieved otherwise (enterprises 2, 3, 10, 28, and 37), or better modifications in the design of the intervention (enterprises 22, and 38).

Analysing the stratified data, it is possible to make some observations on the influence of role and size. Regarding the role, in line with the results of Question 1 the safety manager lean towards a lower value than the "others", probably due to the same reasons highlighted in the answers to Question 1.

Regarding the size, in line with the results of Question 1, the smaller companies provided more positive answers than the larger companies, with the averages in the middle. Like for question 1, the result can be interpreted with the fact that in smaller companies the introduction of a structured approach has a considerable impact in terms of performance.

\section{Question 3 - Usefulness - IMPROVEMENT}

39 of the interviewees confirmed that the improvements introduced by the model compensated the difficulty of use. Analysing the stratified data, it is possible to notice an increase in the difference in 
favour of the "others" with respect to safety managers, confirming the greater satisfaction of the first category than the latter. Also for this question, it is confirmed the greater satisfaction of smaller than larger enterprises, peaking for medium-sized organizations.

\section{Question 4 - Usefulness - RESULT}

22 of the interviewees argue that they would have reached the same results also without the support of the model (note that these are the enterprises in Table 6, column 5, with "++" and "+" in compliance to question 4 of Table 4), while 13 argued that they would have not. In addition, 13 interviewees were not able to answer. Among the 22 that replied positively (i.e. with "++" or "+"), some of the interviewees added that they would have reached the same results with more time (enterprise 36) or with the support of similar models (enterprises 32, and 38). Analysing the stratified data with respect to the role of respondents, in general, the "others" answer negatively (i.e. with "--" or "--"), confirming the usefulness of the model, while the safety managers, on average, believe they would get similar results. Analysing the stratified data with respect to the size of the firm, the negative feedback (i.e. with "--" or "-"), on average, of smaller companies confirm the usefulness of the model, compared to larger ones that, instead, on average believe that they would have obtained the same results without it. The result is in line with the trend highlighted in the previous answers, suggesting that the impact of the tool is different for companies of different sizes because of the different degrees of formality of management systems.

\section{Question 5 - Completeness - MECHANISM \& Question 6 - Completeness - CONTEXTUAL FACTOR}

Most (i.e. 40 out of 50) of interviewees that answered these questions confirmed the completeness of the taxonomies of mechanisms and contextual factors. Analysing the stratified data, the results for both question 5 and question 6 seem to highlight no substantial difference when different roles, firm size and sector is considered, so that it is difficult to interpret this data.

\section{Question 7 - Difficulty of use - STEP}

The most difficult step seemed to be step 7, where the users had to develop design recommendations for the intervention which builds on the results of the four preceding steps. Several interviewees highlighted how they would not select a contextual factor that they consider inadequate in the firm. The result shows a key difference between design of an OHS interventions by researchers under controlled conditions and the design of an interventions by practitioners. The evaluation shows how practitioners tend to minimise the use of resources and match the actual condition of the firm when designing OHS interventions.

\section{Conclusions}

The results of the study show the value of guiding the implementation of OSH interventions through a structured framework. The reasons for this value include the possibility of defining innovative and more effective solutions, a more effective focus on the aspects that should be considered, a more organic and systematic way of structuring the data, and a holistic and comprehensive view on the factors. The model also highlights specific aspects of contextual factors and mechanisms and it organizes the data in a more systematic and structured fashion.

The systematic and holistic view are not necessarily related to the realistic analysis, and could be a result of the implementation of any structured model. Indeed, a systematic and holistic view are among the purposed of several structured models (Hare et al, 2012). On the other hand, stepwise procedures risk of limiting the creativity of the practitioner (Pawson et al., 2005). Realistic analysis avoids this risk thanks to the possibility of discovering the different layers of reality that underpin a specific phenomenon (Pawson, 2002). Different layers of reality are thus the source of innovation, through the exploitation of mechanisms that are usually hidden. Moreover, the key result of the interaction between 
mechanisms and contextual factors seems to be an improved focus and the development of more innovative solutions. Therefore, the results highlight the potential of the realistic analysis, although its relative value with respect to other procedures requires further researches.

Regarding the difficulty of use, the results are apparently in contradiction, since the majority of respondents firstly confirmed that the results compensate the difficulty of use, and after reported that they could have got the same results without the model. However, the contradiction is only apparent. Indeed, when the interviewees better articulated there answer, they confirmed the possibility of getting the same results but with more time or with the support of another structured model. The most difficult step seems to be 7, in which practitioners have to identify the mechanisms that cannot be activated in the current conditions of the company. This result was somehow predictable since it is naturally easy to think in positive terms (what to do, what to activate) rather than on negative terms when designing an $\mathrm{OSH}$ intervention.

The results did not provide strong evidence in favour of the completeness of the model. Indeed, few interviewees answered the question related to the completeness of the model. It was easy to predict the low number of answers to this question, because one of the reasons for the proposition of this model was the difficulty for the practitioners to perform a comprehensive analysis. Therefore, this result partially confirms the need of supporting practitioners with a model for a structured analysis. An indicator for the completeness of the model is the fact that all the relevant factors and mechanisms determining the performance of the workers have been included in the taxonomies.

It is important to underline how the evaluation analysed the outcome of the design process. After the design, the intervention should be actually implemented and its effectiveness should be assessed. This aspect will be investigated in further research using the preliminary results of this study. 


\section{Appendix}

In the table, the (kind of) interventions (reported in the cell) are grouped by mechanisms (on the rows), and divided by (class of) contextual factors (on the columns). In the cell (information about intervention), it is reported (in order) the identifying number of the firm, the firm size, the kind of intervention and the assessment of the adequacy of the contextual factor in the current context of the firm.

Legend (information in the cell)

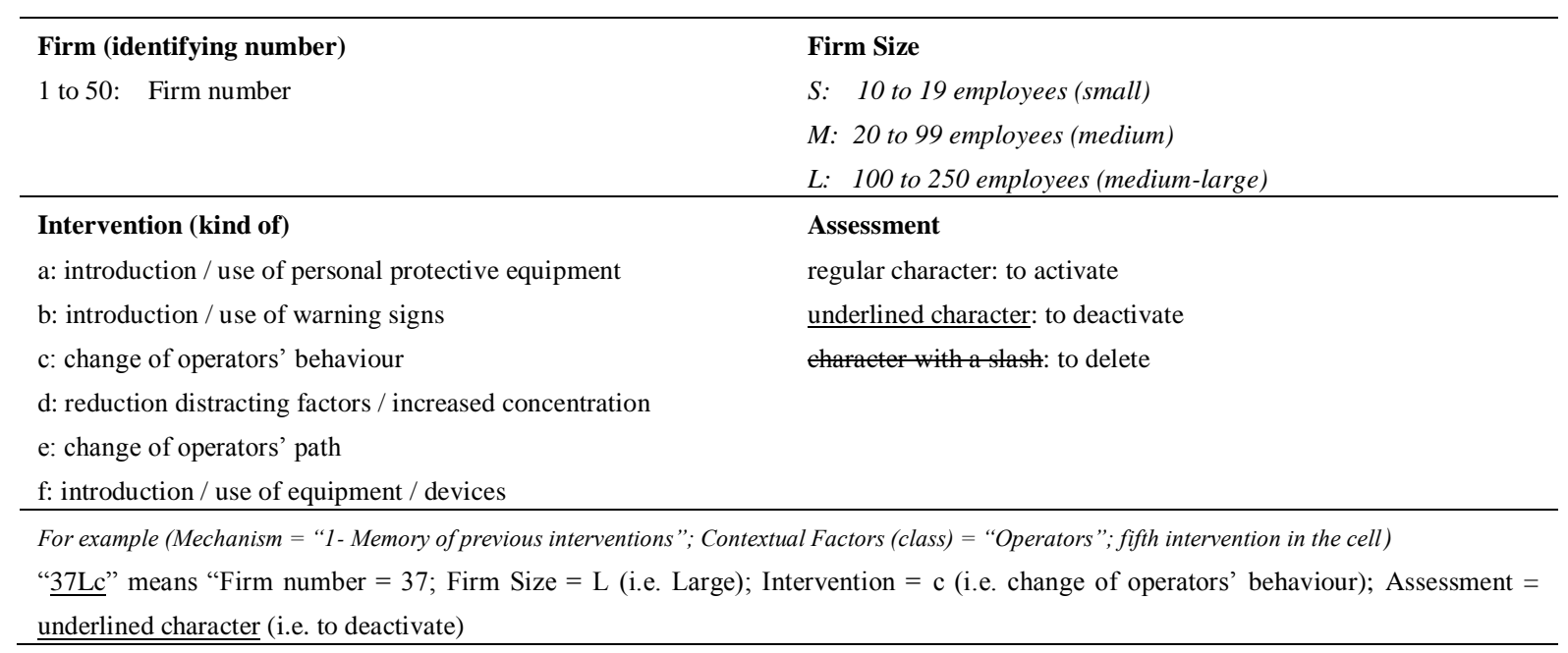

\begin{tabular}{|c|c|c|c|c|}
\hline $\begin{array}{r}\text { CONTEXTUAL } \\
\text { FACTORS } \\
\text { (class) }\end{array}$ & Operators & $\begin{array}{l}\text { Physical work } \\
\text { environment, } \\
\text { equipment and } \\
\text { tools }\end{array}$ & $\begin{array}{l}\text { Organization } \\
\text { factors }\end{array}$ & Team factors \\
\hline \multicolumn{5}{|l|}{ MECHANISM } \\
\hline $\begin{array}{l}1 \text { - Memory of } \\
\text { previous } \\
\text { interventions }\end{array}$ & $\begin{array}{c}2 \mathrm{La} \\
3 \mathrm{Md} \\
14 \mathrm{Mc} \\
31 \mathrm{Mc} \\
\frac{37 \mathrm{Lc}}{43 \mathrm{Mc}} \\
\frac{49 \mathrm{Ma}}{4}\end{array}$ & & & \\
\hline 2 - Anticipation & $\begin{array}{c}8 \mathrm{Lb} \\
16 \mathrm{Sb} \\
18 \mathrm{Sab} \\
38 \mathrm{Lc}\end{array}$ & & $\begin{array}{l}11 \mathrm{Ma} \\
23 \mathrm{Sa}\end{array}$ & \\
\hline $\begin{array}{l}3 \text { - Autonomous } \\
\text { identification of } \\
\text { effective } \\
\text { behaviours }\end{array}$ & $\begin{array}{c}5 \mathrm{Mc} \\
14 \mathrm{Mc} \\
15 \mathrm{Mb} \\
17 \mathrm{Mb} \\
23 \mathrm{Sa} \\
27 \mathrm{Mb} \\
\end{array}$ & $34 \mathrm{Lc}$ & $\begin{array}{c}5 \mathrm{Mc} \\
7 \mathrm{La} \\
12 \mathrm{Ma} \\
13 \mathrm{Ma} \\
14 \mathrm{Mc} \\
15 \mathrm{Mb} \\
16 \mathrm{Sb} \\
17 \mathrm{Mb} \\
18 \mathrm{Sab} \\
19 \mathrm{Ma} \\
20 \mathrm{Ma} \\
21 \mathrm{Ma}\end{array}$ & \\
\hline
\end{tabular}




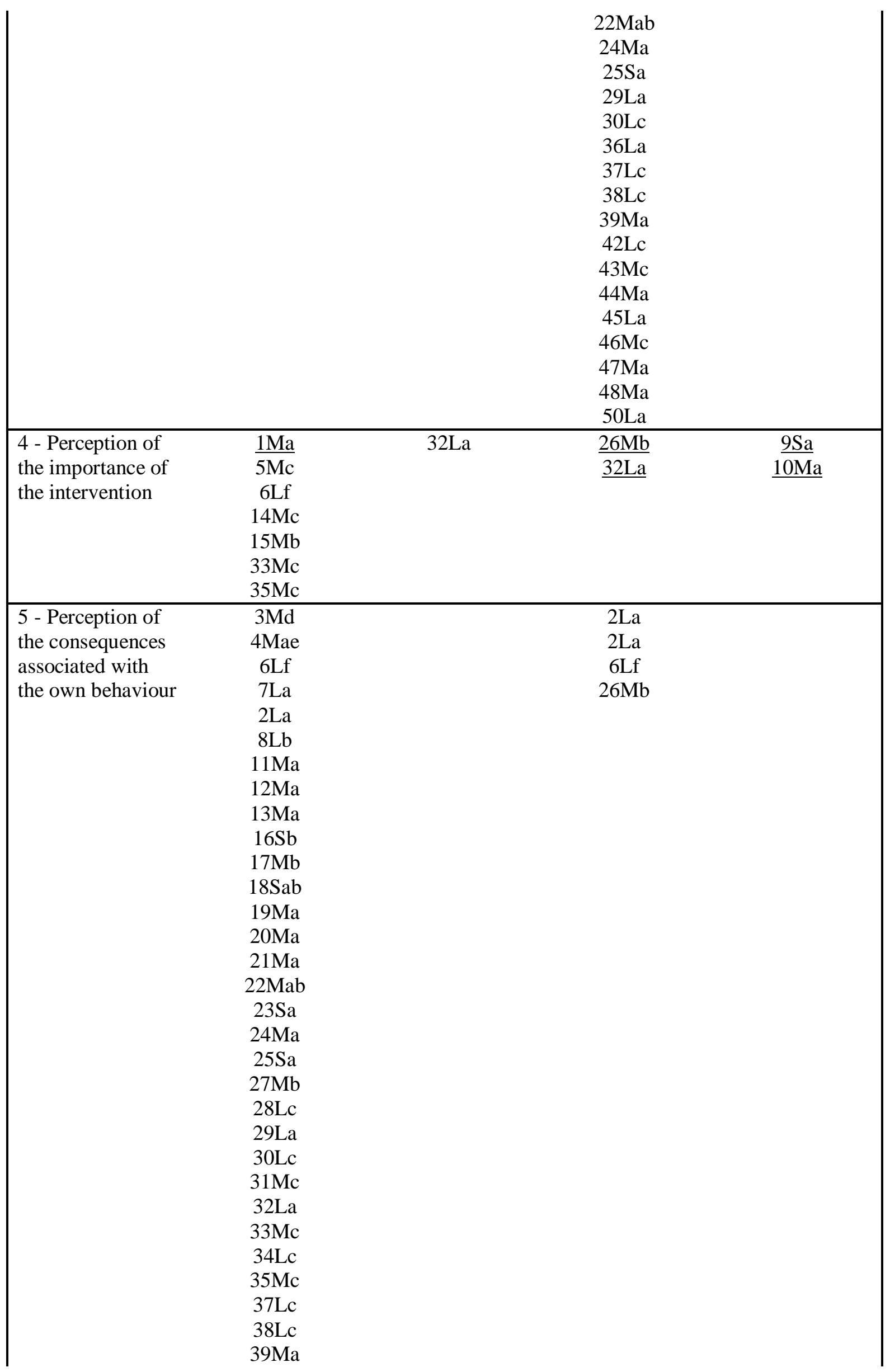




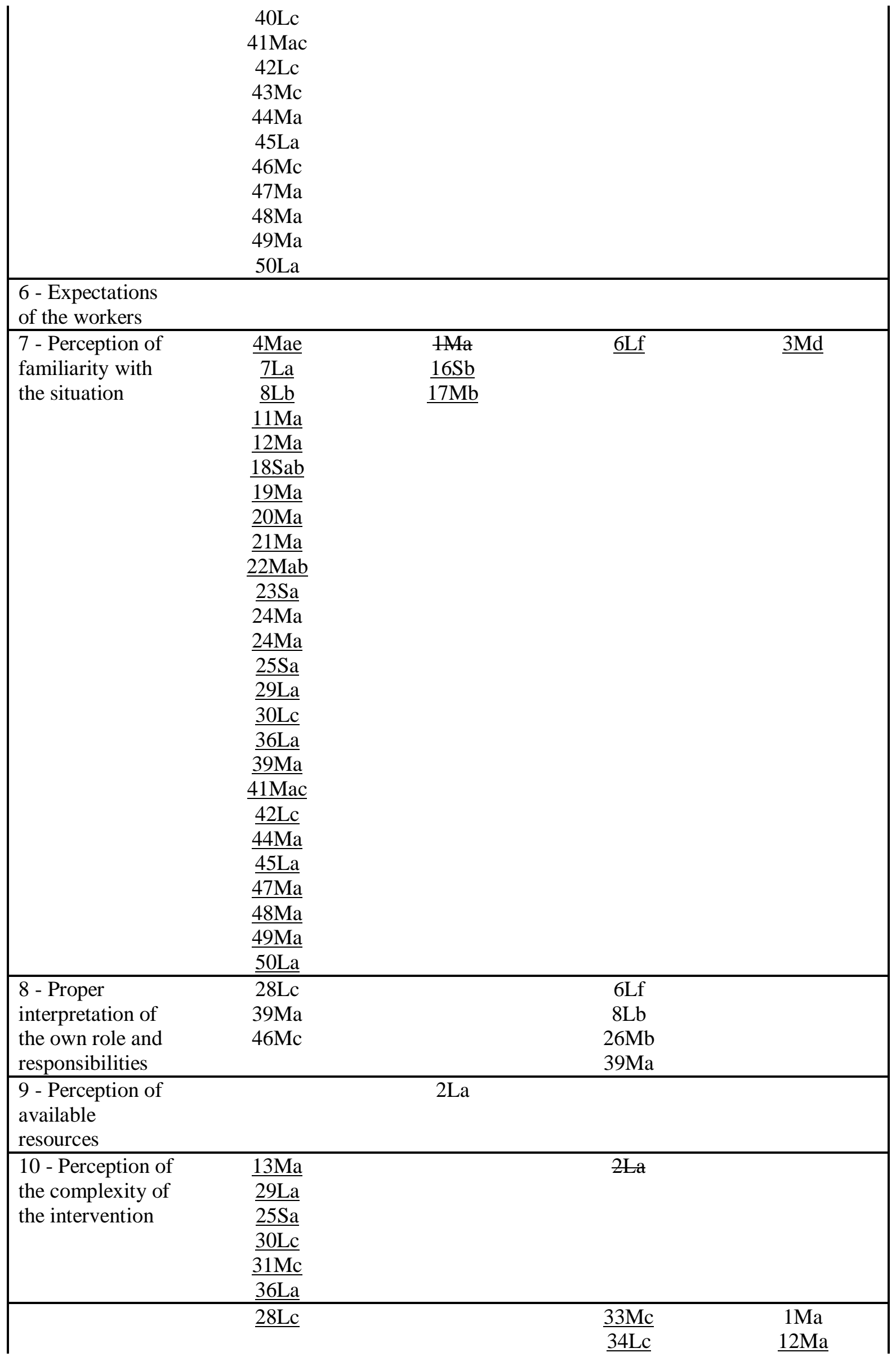




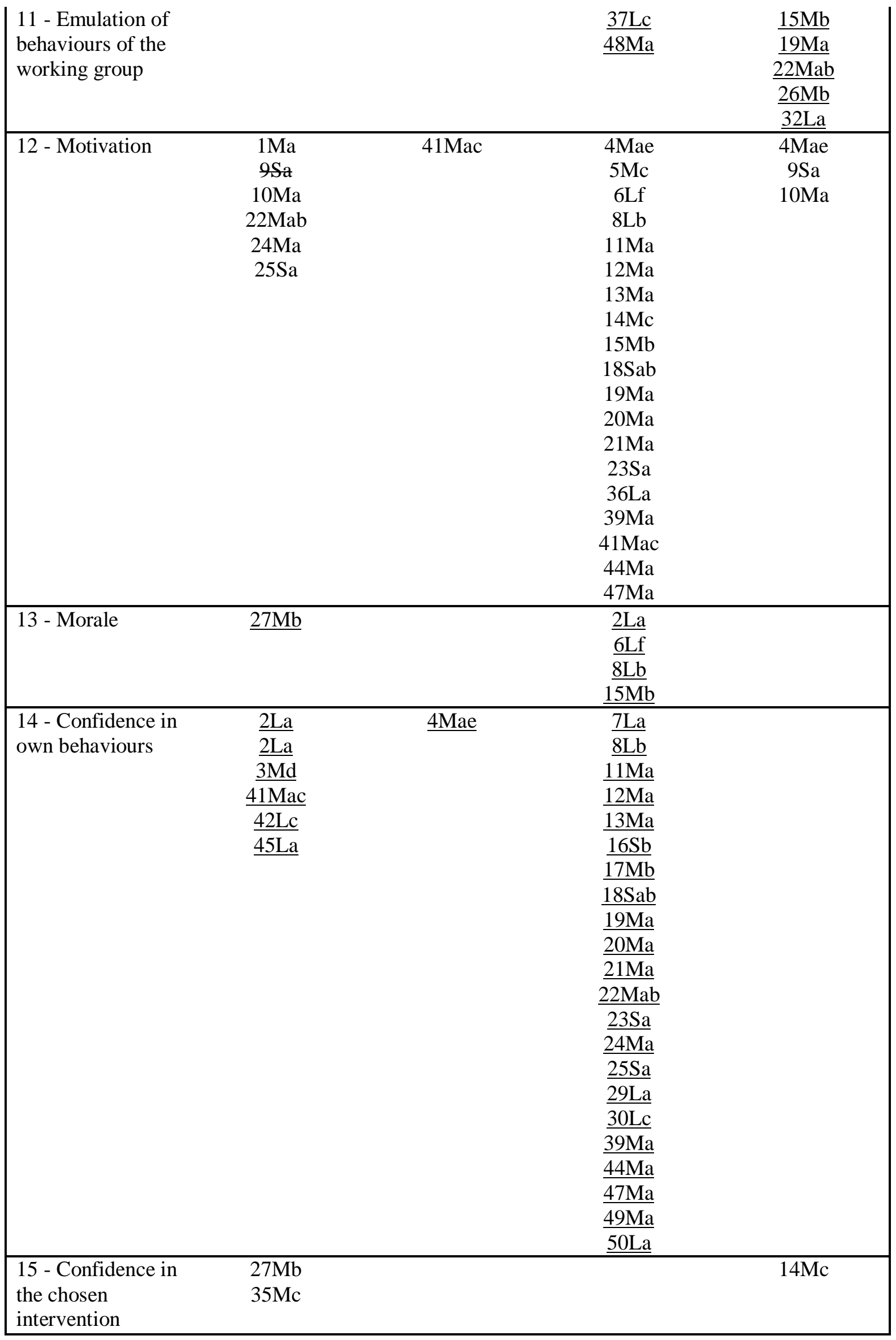




\begin{tabular}{|c|c|c|c|c|}
\hline $\begin{array}{l}16 \text { - Trust in } \\
\text { management and } \\
\text { in the enterprise }\end{array}$ & & & & $8 \mathrm{Lb}$ \\
\hline $\begin{array}{l}17 \text { - Fear of } \\
\text { failure } \\
\end{array}$ & $2 \mathrm{La}$ & $2 \mathrm{La}$ & $2 \mathrm{La}$ & \\
\hline $\begin{array}{l}18 \text { - Stress due to } \\
\text { urgent requests }\end{array}$ & & & $\begin{array}{l}\frac{2 \mathrm{La}}{4 \mathrm{Mae}} \\
\frac{5 \mathrm{Mc}}{6 \mathrm{Lf}} \\
\frac{7 \mathrm{La}}{8 \mathrm{Lb}} \\
\frac{8 \mathrm{LMa}}{13 \mathrm{Ma}} \\
\frac{14 \mathrm{Mc}}{17 \mathrm{Mb}} \\
\frac{20 \mathrm{Ma}}{23 \mathrm{Sa}} \\
\frac{24 \mathrm{Ma}}{25 \mathrm{Sa}} \\
\frac{26 \mathrm{Mb}}{38 \mathrm{Lc}} \\
\frac{39 \mathrm{Ma}}{47 \mathrm{Ma}} \\
\end{array}$ & $\underline{3 \mathrm{Md}}$ \\
\hline $\begin{array}{l}19 \text { - Stress due to } \\
\text { the conflict }\end{array}$ & & & $\begin{array}{l}\frac{5 \mathrm{Mc}}{11 \mathrm{Ma}} \\
\frac{14 \mathrm{Mc}}{21 \mathrm{Ma}} \\
\frac{23 \mathrm{Sa}}{2} \\
\end{array}$ & \\
\hline 20 - Frustration & $\begin{array}{l}\frac{28 \mathrm{Lc}}{30 \mathrm{Lc}} \\
\underline{34 \mathrm{Lc}} \\
\end{array}$ & $\begin{array}{l}\mathrm{La} \\
2 \mathrm{La} \\
\end{array}$ & $\underline{8 \mathrm{Lb}}$ & \\
\hline \multicolumn{5}{|l|}{21 - Uncertainty } \\
\hline 22 - Attention & & $\begin{array}{c}7 \mathrm{La} \\
17 \mathrm{Mb} \\
16 \mathrm{Sb} \\
20 \mathrm{Ma} \\
24 \mathrm{Ma}\end{array}$ & $\begin{array}{c}3 \mathrm{Md} \\
\frac{33 \mathrm{Mc}}{34 \mathrm{Lc}} \\
\frac{35 \mathrm{Mc}}{46 \mathrm{Mc}}\end{array}$ & \\
\hline
\end{tabular}




\section{References}

Astbury, B., \& Leeuw, F. L. (2010). Unpacking black boxes: mechanisms and theory building in evaluation. American journal of evaluation, 31(3), 363-381.

Bonafede, M., Corfiati, M., Gagliardi, D., Boccuni, F., Ronchetti, M., Valenti, A., ... \& Iavicoli, S. (2016). OHS management and employers' perception: differences by firm size in a large Italian company survey. Safety science, $89,11-18$.

Broberg, O., \& Hermund, I. (2004). The OHS consultant as a facilitator of learning in workplace design processes: Four explorative case studies of current practice. International Journal of Industrial Ergonomics, 37(9-10), 810-816.

Brun, J. P., \& Loiselle, C. D. (2002). The roles, functions and activities of safety practitioners: the current situation in Québec. Safety Science, 40(6), 519-536.

Cagno, E., Micheli, G. J. L., Jacinto, C., \& Masi, D. (2014). An interpretive model of occupational safety performance for Small-and Medium-sized Enterprises. International Journal of Industrial Ergonomics, 44(1), 60-74.

Chang, Y. H. J., \& Mosleh, A. (2007). Cognitive modeling and dynamic probabilistic simulation of operating crew response to complex system accidents. Part 2: IDAC performance influencing factors model. Reliability Engineering \& System Safety, 92(8), 1014-1040.

Cutler, D. J. (1997). U.S. Patent No. 5,671,900. Washington, DC: U.S. Patent and Trademark Office.

Eldredge, L. K. B., Markham, C. M., Ruiter, R. A., Kok, G., \& Parcel, G. S. (2016). Planning health promotion programs: an intervention mapping approach. John Wiley \& Sons.

Garrigou, A., \& Peissel-Cottenaz, G. (2008). Reflexive approach to the activity of preventionists and their training needs: Results of a French study. Safety science, 46(8), 1271-1288.

Goldenhar, L. M., LaMontagne, A. D., Katz, T., Heaney, C., \& Landsbergis, P. (2001). The intervention research process in occupational safety and health: an overview from the National Occupational Research Agenda Intervention Effectiveness Research team. Journal of occupational and environmental medicine, 43(7), 616-622.

Griffiths, A. (1999). Organizational interventions: Facing the limits of the natural science paradigm. Scandinavian Journal of Work, Environment \& Health, 589-596.

Hale, A. R., Guldenmund, F. W., Van Loenhout, P. L. C. H., \& Oh, J. I. H. (2010). Evaluating safety management and culture interventions to improve safety: Effective intervention strategies. Safety Science, 48(8), 1026-1035.

Hare, B., \& Cameron, I. (2012). Health and safety gateways for construction project planning. Engineering, Construction and Architectural Management, 19(2), 192-204.

Hasle, P., \& Jensen, P. L. (2006). Changing the internal health and safety organization through organizational learning and change management. Human Factors and Ergonomics in Manufacturing \& Service Industries, 16(3), 269-284.

Hasle, P. (2011). When health and safety interventions meet real-life challenges. Policy and practice in health and safety, 9(1), 3-16.

Hasle, P., Kvorning, L. V., Rasmussen, C. D., Smith, L. H., \& Flyvholm, M. A. (2012). A model for design of tailored working environment intervention programmes for small enterprises. Safety and health at work, 3(3), 181-191. 
Kennedy, C. A., Amick III, B. C., Dennerlein, J. T., Brewer, S., Catli, S., Williams, R., ... \& Franzblau, A. (2010). Systematic review of the role of occupational health and safety interventions in the prevention of upper extremity musculoskeletal symptoms, signs, disorders, injuries, claims and lost time. Journal of occupational rehabilitation, 20(2), 127-162.

Kim, J. W., \& Jung, W. (2003). A taxonomy of performance influencing factors for human reliability analysis of emergency tasks. Journal of loss prevention in the process industries, 16(6), 479-495.

Kompier, M. A., \& Kristensen, T. S. (2001). Organizational work stress interventions in a theoretical, methodological and practical context.

Kvorning, L. V., Hasle, P., \& Christensen, U. (2015). Motivational factors influencing small construction and auto repair enterprises to participate in occupational health and safety programmes. Safety science, 71, 253-263.

Lamontagne, A. D., Keegel, T., Louie, A. M., Ostry, A., \& Landsbergis, P. A. (2007). A systematic review of the job-stress intervention evaluation literature, 1990-2005. International journal of occupational and environmental health, 13(3), 268-280.

Legg, S. J., Olsen, K. B., Laird, I. S., \& Hasle, P. (2015). Managing safety in small and medium enterprises.

Micheli, G. J., \& Cagno, E. (2010). Dealing with SMEs as a whole in OHS issues: warnings from empirical evidence. Safety science, 48(6), 729-733.

Mohaghegh, Z., \& Mosleh, A. (2009). Incorporating organizational factors into probabilistic risk assessment of complex socio-technical systems: Principles and theoretical foundations. Safety Science, 47(8), 1139-1158.

Murta, S. G., Sanderson, K., \& Oldenburg, B. (2007). Process evaluation in occupational stress management programs: a systematic review. American Journal of Health Promotion, 21(4), 248-254.

Nielsen, K., \& Randall, R. (2013). Opening the black box: Presenting a model for evaluating organizational-level interventions. European Journal of Work and Organizational Psychology, 22(5), 601-617.

Nytrø, K., Saksvik, P. Ø., Mikkelsen, A., Bohle, P., \& Quinlan, M. (2000). An appraisal of key factors in the implementation of occupational stress interventions. Work \& Stress, 14(3), 213-225.

Olsen, O., Albertsen, K., Nielsen, M. L., Poulsen, K. B., Gron, S. M. F., \& Brunnberg, H. L. (2008). Workplace restructurings in intervention studies-a challenge for design, analysis and interpretation. BMC Medical Research Methodology, 8(1), 39.

Olsen, K. (2012). Occupational health and safety professional's strategies to improve working environment and their self-assessed impact. Work, 41(Supplement 1), 2625-2632.

Pawson, R., Tilley, N., \& Tilley, N. (1997). Realistic evaluation. Sage.

Pawson, R. (2002). Evidence-Based policy: The Promise of Realist Synthesis, Centre for Evidence Based Policy \& Practice Working Paper 4. In Queen Mary, University of London.

Pawson, R., Greenhalgh, T., Harvey, G., \& Walshe, K. (2005). Realist review-a new method of systematic review designed for complex policy interventions. Journal of health services research \& policy, 10(1_suppl), 21-34.

Pedersen, L. M., Nielsen, K. J., \& Kines, P. (2012). Realistic evaluation as a new way to design and evaluate occupational safety interventions. Safety Science, 50(1), 48-54.\# 
Robson, L. S. (2001). Guide to evaluating the effectiveness of strategies for preventing work injuries; how to show whether a safety invervention really works. Available online: https://www.cdc.gov/niosh/docs/2001-119/pdfs/2001-119.pdf

Semmer, N. K. (2006). Job stress interventions and the organization of work. Scandinavian journal of work, environment \& health, 515-527.

Van Scheppingen, A. R., Ten Have, K. C., Zwetsloot, G. J., Kok, G., \& van Mechelen, W. (2015). Determining organisation-specific factors for developing health interventions in companies by a Delphi procedure: Organisational Mapping. Journal of health psychology, 20(12), 1509-1522.

Whysall, Z., Haslam, C., \& Haslam, R. (2006). Implementing health and safety interventions in the workplace: An exploratory study. International Journal of Industrial Ergonomics, 36(9), 809-818.

Zohar, D. (2014). Safety climate: Conceptualization, measurement, and improvement. The Oxford handbook of organizational climate and culture, 317-334. 